\title{
BIBLIOGRAFÍA
}

SECCIONES: Agricultura y alimentación / Ciencias de las religiones y Teología / Derecho / Desarrollo y cooperación / Desarrollo rural y sociología rural / Economía / Economía social / Educación y Psicología / Empresa / Ética / Filosofía / Historia / Historia social y económica / Pensamiento social cristiano / Política / Sociología / Varios

Autores: Francisco BOCERO DE LA ROSA es Director de Comunicación y Relaciones institucionales de la Universidad Loyola Andalucía; Rosa MElero Bolaños y Mercedes RuIz LOZANO son profesoras de la Universidad Loyola Andalucía; Leandro SEQUEIROS SAN ROMÁN es catedrático jubilado de universidad y miembro de la Cátedra CTR, Universidad Pontificia Comillas, Madrid. Y los miembros de la redacción

Coordinador: Adolfo Rodero FranganiLlo.

\section{REPERTORIO DE BIBLIOGRAFÍA SOBRE LOS DISCURSOS DEL ODIO}

La actualidad y los múltiples perfiles que presenta el tema del editorial sobre "Los discursos del odio: una nueva amenaza a la construcción democrática de la tolerancia" puede hacer útil para el lector la inclusión de un repertorio bibliográfico para profundizar en el conocimiento de este tema. A tal fin se relacionan a continuación las obras que consideramos que ilustran mejor los distintos aspectos temáticos y disciplinares de la cuestión.

\section{Bibliografia sobre los discursos del odio}

1. Alastuey Dobón, C. (2014) “La reforma de los delitos de provocación al odio y justificación del genocidio en el Proyecto de Ley de 2013: consideraciones críticas": La Ley (6-II-2014, n. 8245)
2. AlcáCer Guirao, R. (2012) "Discurso del odio y discurso político: En defensa de la libertad de los intolerantes": Revista electrónica de ciencia penal y criminología, ISSN-e 1695-0194, 14. 
3. Alcácer Guirao, R. (2013) "Libertad de expresión, negación del holocausto y defensa de la democracia. Incongruencias valorativas en la jurisprudencia del TEDH": Revista española de derecho constitucional 33 (n. 97)

4. Alcácer Guirao, R. (2015) "Víctimas y disidentes. El "discurso del odio" en EE. UU. y Europa": Revista española de derecho constitucional, 35 (n. 103)

5. Alonso Álamo, M. (2012) "Sentimientos y Derecho penal": Cuadernos de Política Criminal, 106

6. Apel, K.O. (1998) "La ética del discurso como ética de la responsabilidad", en Teoría de la verdad y Ética del Discurso, Barcelona, Paidós.

7. BADER, V. (2014) "Free speech or Nondiscrimination as trump? Reflections on contextualized reasonable balancing and its limits": Journal of Ethnic and Migration Studies, 40/2.

8. Boix Palop, A. (2002) "Libertad de expresión y pluralismo en la red": Revista española de derecho constitucional, 22 (n. 65), 133-182.

9. BORJA JIMÉNEZ, E. (1999) Violencia y criminalidad racista en Europa Occidental: la respuesta del Derecho Penal, Granada, Comares.

10. Bustos Gisbert, R. (2015) "Libertad de expresión y discurso negacionista", en AAVV (2015) Libertad de expresión y discursos del odio, Madrid.

11. Català । Bas, A. H. y Pérez I Seguí, Z. (2007) "La negación del holocausto. A propósito de la STC 235/2007, de 7 de noviembre de 2007": Revista europea de derechos fundamentales, 10.
12. Caruso, C. (2013) "Dignità degli "altri" e spazi di libertà degli "intolleranti": Una rilettura dell'art. 21 Costi": Quaderni costituzionali 4, 795-821.

13. Carrillo Donaire, J. A. (2015) "Libertad de expresión y "discurso del odio" religioso: la construcción de la tolerancia en la era postsecular": Revista de Fomento Social 70, 205-243.

14. Cuerda Arnau, M. L. (1988) "Algunas reflexiones críticas acerca de la apología": Revista del Poder Judicial n. 9.

15. Cuerda Arnau, M. L. (1999) "El denominado delito de apología de genocidio": Revista del Poder Judicial, n. 56.

16. Cuerda Arnau, M. L. (2007) "El nuevo delito político: apología, enaltecimiento y opinión, en la generalización del Derecho Penal de excepción: tendencias legislativas": Estudios de Derecho Judicial, $\mathrm{n}^{\circ} 128$.

17. EnzesbenGuer, H. M. (2007) El perdedor radical. Ensayo sobre los hombres del terror, Barcelona, Anagrama.

18. Glukcsman, A. (2005) El discurso del odio, Madrid, Santillana.

19. Jeremy, A. (2006) "Practical Implications of the Enactment of the Racial and Religious Hatred Act": Ecclesiastical Law Journal, 9, 2006.

20. LANDA Gorostiza, J.-M. (1999) La intervención penal frente a la xenofobia. Bilbao, Universidad del País Vasco, 2000.

21. LANDA GorostizA, J.-M. (2001) La política criminal contra la xenofobia y las tendencias expansionistas del Derecho Penal, Granada, Comares. 
22. Larsen, E. (2014) "Towards the Blasphemous Self: Constructing Societal Identity in Danish Debates on Blasphemy Provision in the Twentieth and Twentyfirst Centuries": Journal of Ethnic and Migration Studies, 40/2.

23. LEWIS, A. (2007) Freedom for the Thought That We Hate. A Biography of the First Amendment, Basic Books, Nueva York.

24. Martínez-Torrón, J. (2016) "Libertad de expresión y lenguaje ofensivo: algunos criterios prácticos de análisis jurídico": El Cronista del Estado Social y Democrático de Derecho, n. 60.

25. Moretón Toquero, A. (2012) "El ciberodio, la nueva cara del mensaje del odio: entre la cibercriminalidad y la libertad de expresión": Revista Jurídica de Castilla y León, 27.

26. Muñoz Machado, S. (2013): Los itinerarios de la libertad de palabra, Barcelona, Planeta.

27. ParekH, B. (2008) Rethinking Multiculturalism: Cultural Diversity and Political Theory, Harvard UP, 2002; y European Liberalism and 'the Muslim Question': Does Intercultural Dialogue Make Sense? (ISIM Papers), Amsterdam, Amsterdam University.

28. Poliakov, L. (2011) Breviario del odio, Barcelona, Cómplice.

29. Post, R (2009) "Hate Speech", en Extreme Speech and Democracy, Nueva York, Oxford University.

30. Revenga SánChez, M. (2005) "El tránsito hacia (y la lucha por) la Democracia Militante en España": Revista de derecho político, n. 62.
31. Revenga Sánchez, M. (2015) "Discursos del odio y modelos de democracia": El Cronista del Estado Social y Democrático de Derecho, n. 50.

32. Rey Martínez, F. (2014) "Racismo líquido": Claves de Razón Práctica, n. 237.

33. RodríGuez-IzQuierdo Serrano, M. (2014) "La libertad deexpresióny la jurisprudencia del Tribunal de Justicia de la Unión Europea": Estudios de Deusto. Revista de la Universidad de Deusto, 62/2.

34. RodríGuez-IzQuierdo SerRano, M. (2015) "El discurso del odio a través de Internet", en Revenga SÁNCHEZ, M., coord. (2015) Libertad de expresión y discursos delodio, Madrid, Universidad de Alcalá de Henares.

35. RodRIGUez MONTAÑÉs, T. (2012) Libertad de expresión, discurso extremoy delito, Valencia, Tirant lo Blanch.

36. Sandierg, R. y Doe, N. (2008) "The Strange Death of Blasphemy": Modern Law Review, 71.

37. Teruel Lozano, G. M. (2014) "Libertad de expresión y censura en Internet": Estudios de Deusto: Revista de la Universidad de Deusto, 62/2.

38. Teruel Lozano, G.M. (2015) “La libertad de expresión frente a los delitos de negacionismo y de provocación al odio y a la violencia: sombras sin luces en la reforma del código penal", Indret: Revista para el Análisis del Derecho, NN. 4, 2015.

39. TOdorov, T. (2014) El miedo a los bárbaros, Barcelona, Galaxia Gutenberg.

40. Vázquez Alonso, V. J. (2014): "La libertad artística: una primera aproximación": Estudios de Deusto: Revista de la Universidad de Deusto 62/2. 